\title{
ALTERATIONS OF LOCAL BLOOD FLOW IN THE PENUMBRA ZONE OF LOCAL CEREBRAL INFARCTION
}

\author{
${ }^{1}$ Tchlikadze N., ${ }^{2}$ Arabuli M., ${ }^{2}$ Nikuradze N., ${ }^{1.3}$ Solomonia R., ${ }^{3}$ Mitagvaria N. \\ ${ }^{I}$ Ilya State University \\ ${ }^{2}$ Tbilisi State Medical University \\ ${ }^{3}$ Ivane Beritashvili Center for Experimental Biomedicine \\ Tbilisi, Georgia
}

DOI: https://doi.org/10.31435/rsglobal_ws/31052019/6513

$\begin{array}{ll}\text { ARTICLE INFO } & \text { ABSTRACT } \\ \begin{array}{l}\text { Received: 11 March 2019 } \\ \text { Accepted: 25 May 2019 }\end{array} & \begin{array}{l}\text { The main objective of this study was to reveal the circulatory changes in } \\ \text { Published: 31 May 2019 }\end{array} \\ \begin{array}{l}\text { the Penumbra zone of stroke, which was induced by the photochemical } \\ \text { method in the cerebral cortex of the rats. It has been revealed that the } \\ \text { maximum reduction in blood supply in the penumbra zone during }\end{array} \\ \begin{array}{l}\text { KEYWORDS } \\ \text { photochemical Stroke, Penumbra, } \\ \text { Blood Flow, Cerebral Cortex, Rats. }\end{array} & \begin{array}{l}\text { process of inducing thrombosis of vessels. Therapeutic intervention to save } \\ \text { the cells of the Penumbra zone, which are in the initial stages of apoptosis, } \\ \text { it is advisable to carry out in the first } 12 \text { hours after the onset of stroke. }\end{array}\end{array}$

Citation: Tchlikadze N., Arabuli M., Nikuradze N., Solomonia R., Mitagvaria N. (2019) Alterations of Local Blood Flow in the Penumbra Zone of Local Cerebral Infarction. World Science. 5(45), Vol.2. doi: 10.31435/rsglobal_ws/31052019/6513

Copyright: (C) 2019 Tchlikadze N., Arabuli M., Nikuradze N., Solomonia R., Mitagvaria N. This is an open-access article distributed under the terms of the Creative Commons Attribution License (CC BY). The use, distribution or reproduction in other forums is permitted, provided the original author(s) or licensor are credited and that the original publication in this journal is cited, in accordance with accepted academic practice. No use, distribution or reproduction is permitted which does not comply with these terms.

Introduction. Approximately $80-85 \%$ of total number of strokes is due to ischemic cerebral infarctions (ischemic strokes). Stroke is considered as one of the leading causes of mortality and disability prevalence in the population. In the United States, ischemic brain injury was the third leading cause of mortality and the first cause of adult disability, respectively (Ahmed et al., 2000).

One of the main objectives to study of the pathogenetic mechanisms for ischemic brain injuries is determination of the so-called "Therapeutic Window" and development of adequate treatment methods for maximum possible reduction of the potential for brain injury.

In a focal cerebral stroke, the ischemic region consists of a central region (ischemic focus), with a sharply reduced cerebral blood flow, and a more distal portion of the so-called penumbra zones that are partially supplied with blood by collaterals of adjacent intact vessels (Bhardwaj et al., 2003, Ramos-Cabrer et al., 2011). In ischemic focus, depending on the severity of the cerebral blood flow and its duration, irreversible damage may develop, up to and including a local cerebral infarction. Therefore, timely intervention and the use of so called "Therapeutic Window" to prevent development of infarction, and in case of its formation, taking measures to rescue cellular elements of the penumbra zone from development of irreversible injuries and to restore their structural-functional organization are of great importance.

It should be emphasized that despite the urgency of the local cerebral infarction problem, the issues related to morphological and functional changes in the Penumbra zone have been insufficiently studied. The issues of structural and functional rearrangements in the Penumbra zone were studied in more detail with the use of models of short-term occlusion of the middle cerebral artery and subsequent reperfusion. Although in this case, the basic data on morphological rearrangements are based on light-optical studies, and data on ultrastructural shifts in neurons and glial cells of the Penumbra zone are very scarce. Herewith, these data are often contradictory. For example, some researchers, studying the issues related to the neuron injury and death in the Penumbra zone, believe 
that the selective neuron death in the Penumbra zone occurs via apoptosis (Wang et al., 2001), other authors believe that neurons die via both apoptosis and necrosis (Zhao et al., 2001, 2002), as to the third opinion, selective neuronal necrosis occurs in the Penumbra zone (Lehrmann et al., 1997). As for the processes of development of structural changes in the penumbra zone of local infarction, induced by photochemical method, there is practically no data /evidence in this regard.

Most of the methods for the study of biochemical, morphological and metabolic disorders in the development of cerebral stroke, due to their invasiveness, often endangering the patient's life, are not applicable in the clinical setting.

Therefore, animal models of global and focal ischemia are widely used to characterize the mechanisms laid the foundation to the ischemic brain injuries, to test the therapeutic effect of new anti-ischemic preparations, and approbation of theoretical and clinical hypotheses. One of them is the method of photochemically induced focal cerebral infarction (Watson et al., 1985). At this stage, main objective of the current study was the investigation of circulatory changes in the Penumbra zone, induced by photochemical method of local cortex infarction of cerebral hemispheres in rats.

Materials and methods. The experiments were carried out on male Wistar Rats, $150-200 \mathrm{~g}$ of weights. All experimental procedures were conducted on the animals anesthetized with $\mathrm{i} / \mathrm{p}$ administration of a $4 \%$ solution of chloral hydrate $(1 \mathrm{ml} / 100 \mathrm{~g}$ body weight).

All experiments were conducted strictly according to international standards adopted by the Committee on Bioethics of I. Beritashvili Center for Experimental Biomedicine.

\section{The Model of Induced Local Cerebral Infarction.}

An experimental model of local cortical infarction of cerebral hemispheres, based on the method of photochemically-induced vascular thrombosis, has been used (Watson et al., 1985). As is known, injection of photosensitive dye (Rose Bengal) administered to the animals, followed by transcranial intense illumination of cerebral cortex specific area by halogen lamp leads to the formation of ischemic focus in this area.

Under the influence of the light beam, a photochemical reaction occurs in photosensitive dye, resulting in appearance of free oxygen radicals, causing vascular endothelial injury, damage of platelet membrane, their aggregation, vessel wall adhesion and, ultimately, vascular system occlusion.

Due to vascular endothelial injury, the permeability of the capillary walls increases; occurs brain swelling, thus exacerbating brain ischemic injury. The thrombus formation is visually manifested at the 30th minute of illumination and lasts approximately 4 hours (Dietrich et al., 1987; Van Reempts et al., 1987). A partial modification of this method, tested in a laboratory for studying cerebral metabolism regulatory mechanisms at the I. Beritashvili Institute of Physiology of the Georgian Academy of Sciences has been applied (Mitagvaria, Nebieridze et al., 2001; Mitagvaria, Bakhutashvili et al., 2001). Implementing this method, the following procedures have been carried out: solution of photosensitive dye Rose Bengal $(0.13 \mathrm{ml}$ of $0.75 \%$ solution, per $100 \mathrm{~g}$ of weight $)$ heated up to $37^{\circ} \mathrm{C}$ was administered into femoral vein of anesthetized animals for 2-3 minutes. Then the animals were placed in a stereotactic apparatus, skulls were exposed and transcranial illumination of frontal-parietal cerebral cortex was carried out with a halogen lamp 250W using optical fiber light guide (diameter - $2 \mathrm{~mm}$ ) for 60 minutes.

The final power emitted by a light source (at the skull surface) was equal to $64 \mathrm{~W} / \mathrm{cm}^{2}$. Herewith, ischemic brain damage was clearly expressed in the illuminated region of cerebral cortex (Fig. 1) and extended to the adjacent areas with reduced-intensity. The volumetric shape of damaged tissue is similar to a truncated cone.

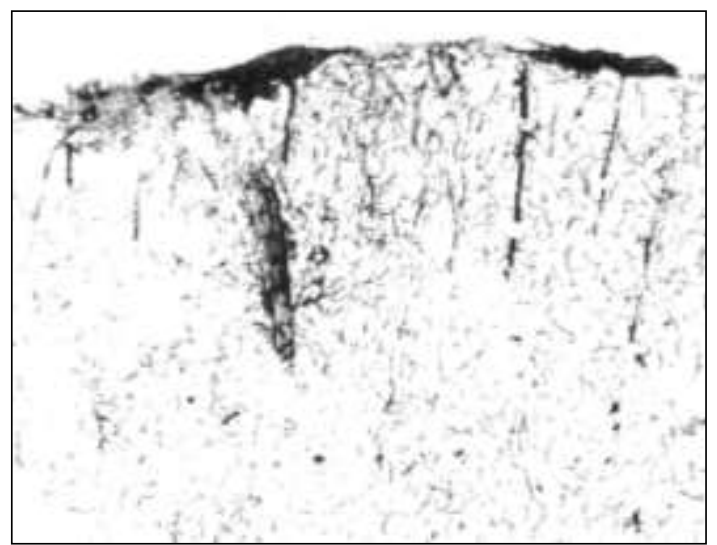

Fig. 1. The frontal-parietal area of cerebral cortex injured by infarction in rats. A large number of thrombosed vessels are well-differentiable (vol. x3, approx. x15) 


\section{Experimental Paradigm.}

Experiments were carried out in 5 animal groups consisting of white rats. There were 6 animals in each group. In all animals, cerebral cortex infarction was induced by the method described above. After completion of the transcranial illumination of frontal-parietal cerebral cortex in 4 hours for the first group of animals, and, in 12, 24, 48 and 96 hours for the II - V groups, respectively, the measurements of systemic arterial pressure (SAP) and local blood flow (LBF) have been performed in the Penumbra zone. For providing the monitoring, the measurements of local blood flow on the contralateral side of cerebral cortex in the symmetrical to the Penumbra zone were also carried out.

Prior to the measurements, all animals (except the first group animals) were anesthetized with chloral hydrate again and, after placing them in a stereotactic apparatus, the skull bilateral trepanation (hole diameter $-2-3 \mathrm{~mm}$ ) was carried out in the penumbra zone as well as symmetric zone on the contralateral side. In animals of the first group, those, measurements on which were carried out in 4 hours after completing the illumination process, there was no need for repeated anesthesia.

After cranial trepanation, active electrodes (for measurement of local blood flow) were implanted in the cerebral cortex required areas without any extra fixations, and reference electrode was fixed under the skin in the immediate vicinity to the trepanation hole. After that, micro-cuff was put on the animal tail to measure systemic arterial pressure. Measurements of both local blood flow and systemic arterial pressure were performed three times at 15-minute intervals. The average value of the three dimensions was considered as the result obtained after experiment.

Measurement of local blood flow $(\mathrm{LBF})$ in the cerebral cortex.

Hydrogen clearance technique was used to measure the LBF. The simplest scheme of method implementation consists of measuring (platinum wire, $100 \mu \mathrm{m}$ in diameter) and reference $(\mathrm{Ag}-\mathrm{AgCl}, \mathrm{a}$ plate, $2-3 \mathrm{~mm}$ of diameter) electrodes dropped in the Polarographic circuit.

The principle of measurement consists in registering the clearance curve (leaching) of molecular hydrogen administered into brain tissue either via the inhalation route or injection into arterial system. The velocity of hydrogen clearance depends on the tissue blood flow intensity and its calculation is carried out according to the well-known method of "initial inclination". As a polarograph, OH-105 universal polarography (OH- 105, Radelkis, Hungary) has been used. Usually, polarization voltage for Hydrogen is $+0.20-0.25 \mathrm{~V}$. This method can be applied at both chronic and acute experiments. The calculation results obtained are characterized by high accuracy.

Measurement of systemic arterial pressure.

Systemic arterial pressure was measured discretely using the device "Artery" (developed by prof. G. Abuladze). Small-size cuff was placed snugly around the tail of the animal, which was continuously heating up to $37^{\circ} \mathrm{C}$. After measuring systolic and diastolic blood pressure by oscilloscope, the average arterial pressure was calculated.

\section{Statistical analysis of the data obtained.}

The results of all physiological measurements were processed statistically by the ANOVA Analysis Tool Package, available in EXCEL for WINDOWS. Reliability of the differences was evaluated by the Student's t-criterion for both pair and group data.

\section{The obtained results and their analysis.}

The absolute values of all the measurements performed are given in Table №1, and the alterations in the local blood flow in the Penumbra zone, expressed as a percentage of initial value, are shown in Fig. 2.

According to the obtained data, in 4 hours after completion of transcranial illumination, the level of blood flow in the Penumbra zone was $30.5 \pm 1.6 \mathrm{ml} / 100 \mathrm{~g} / \mathrm{min}$ in average but in the symmetric zone of the contralateral hemisphere $-58.5 \pm 1.82 \mathrm{ml} / 100 \mathrm{~g} / \mathrm{min}$, respectively. Statistically, the difference between these values is of great significance $(\mathrm{P}<0.01)$. In other words, within four hours the blood supply in the Penumbra zone decreased by $48 \%$. In 12 hours, the changes/alterations mentioned above resulted in the following values: local blood flow in the Penumbra zone $-17.8 \pm 1.0 \mathrm{ml} / 100 \mathrm{~g} / \mathrm{min}$, and in the contralateral (control) side $-55.3 \pm 2.7$; in this case the difference is statistically reliable $(\mathrm{P}<0.01)$ and decrease is equal to $78 \%$. In another 12 hours, i.e. 24 hours after the completion of cerebral cortex transcranial illumination, the average level of blood flow in the Penumbra zone was approximately $16.4 \%$ of the initial level $(10.1 \pm 0.74 \mathrm{ml} / 100 \mathrm{~g} / \mathrm{min}$ in the Penumbra zone versus $61.5 \pm 3.2 \mathrm{ml} / 100 \mathrm{~g} / \mathrm{min}$ in the intact contralateral side). The level of local blood flow in the Penumbra zone registered within 24 hours following the illumination process was minimal. The measurements carried out after 48 hours revealed a partial restoration of blood supply that, in comparison with the previous (24 hours), showed about $7 \%$ increase (blood flow level in the Penumbra zone was $13 \pm 0.64 \mathrm{ml} / 100 \mathrm{~g} / \mathrm{min}$, and on the contralateral side - 55 \pm 2.9 $\mathrm{ml} / 100 \mathrm{~g} / \mathrm{min}$, respectively). 
Table 1. The levels of local blood flow in the Penumbra zone as well as the intact, symmetric zone of contralateral hemisphere, and systemic arterial pressure in 4, 12, 24 hours, 2 and 4 days after the illumination of the zone of potential cerebral cortical stroke using a Halogen Lamp.

\begin{tabular}{|c|c|c|c|c|}
\hline \multirow{2}{*}{ 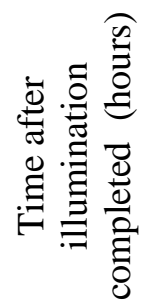 } & \multirow{2}{*}{$\begin{array}{l}\text { Animal } \\
\text { № № }\end{array}$} & \multicolumn{2}{|c|}{$\begin{array}{l}\text { The level of local blood flow in the cerebral } \\
\text { cortex } \\
(\mathrm{ml} / 100 \mathrm{~g} / \mathrm{min})\end{array}$} & \multirow{2}{*}{$\begin{array}{c}\text { Systemic arteria } \\
\text { pressure } \\
(\mathrm{mm} \mathrm{Hg})\end{array}$} \\
\hline & & $\begin{array}{l}\text { In the symmetric zone } \\
\text { of contralateral } \\
\text { hemisphere }\end{array}$ & $\begin{array}{l}\text { In the Penumbra zone of } \\
\text { photochemically } \\
\text { induced stroke }\end{array}$ & \\
\hline \multirow{6}{*}{4} & 1 & 58 & 32 & 90 \\
\hline & 2 & 55 & 26 & 100 \\
\hline & 3 & 62 & 34 & 105 \\
\hline & 4 & 60 & 36 & 100 \\
\hline & 5 & 64 & 28 & 92 \\
\hline & 6 & 52 & 27 & 96 \\
\hline \multicolumn{2}{|c|}{$M \pm m$} & $58.5 \pm 1.8$ & $30.5 \pm 1.6$ & $97.1 \pm 2.3$ \\
\hline & & \multicolumn{2}{|c|}{$P<0.01$} & \\
\hline \multirow{6}{*}{12} & 1 & 49 & 19 & 88 \\
\hline & 2 & 66 & 22 & 91 \\
\hline & 3 & 50 & 15 & 110 \\
\hline & 4 & 52 & 17 & 79 \\
\hline & 5 & 54 & 16 & 95 \\
\hline & 6 & 61 & 18 & 90 \\
\hline \multicolumn{2}{|c|}{$M \pm m$} & $55.3 \pm 2.7$ & $17.8 \pm 1.0$ & $92.2 \pm 4.1$ \\
\hline & & & 0.01 & \\
\hline \multirow{6}{*}{24} & 1 & 72 & 13 & 100 \\
\hline & 2 & 63 & 11 & 117 \\
\hline & 3 & 57 & 9 & 96 \\
\hline & 4 & 68 & 11 & 83 \\
\hline & 5 & 59 & 9 & 88 \\
\hline & 6 & 50 & 8 & 92 \\
\hline \multicolumn{2}{|c|}{$M \pm m$} & $61.5 \pm 3.2$ & $10.1 \pm 0.7$ & $96.0 \pm 4.8$ \\
\hline & & & 0.01 & \\
\hline \multirow{6}{*}{48} & 1 & 55 & 13 & 94 \\
\hline & 2 & 58 & 15 & 115 \\
\hline & 3 & 54 & 12 & 102 \\
\hline & 4 & 67 & 11 & 98 \\
\hline & 5 & 46 & 13 & 89 \\
\hline & 6 & 50 & 14 & 90 \\
\hline \multicolumn{2}{|c|}{$M \pm m$} & $55 \pm 2.9$ & $13 \pm 0.6$ & $98.0 \pm 3.9$ \\
\hline & & & 0.01 & \\
\hline \multirow{6}{*}{96} & 1 & 66 & 16 & 99 \\
\hline & 2 & 68 & 19 & 95 \\
\hline & 3 & 75 & 21 & 86 \\
\hline & 4 & 59 & 18 & 102 \\
\hline & 5 & 63 & 16 & 103 \\
\hline & 6 & 51 & 15 & 88 \\
\hline \multirow{2}{*}{\multicolumn{2}{|c|}{$M \pm m$}} & $63.6 \pm 3.3$ & $17.5 \pm 0.9$ & $95.5 \pm 2.9$ \\
\hline & & & 0.01 & \\
\hline
\end{tabular}




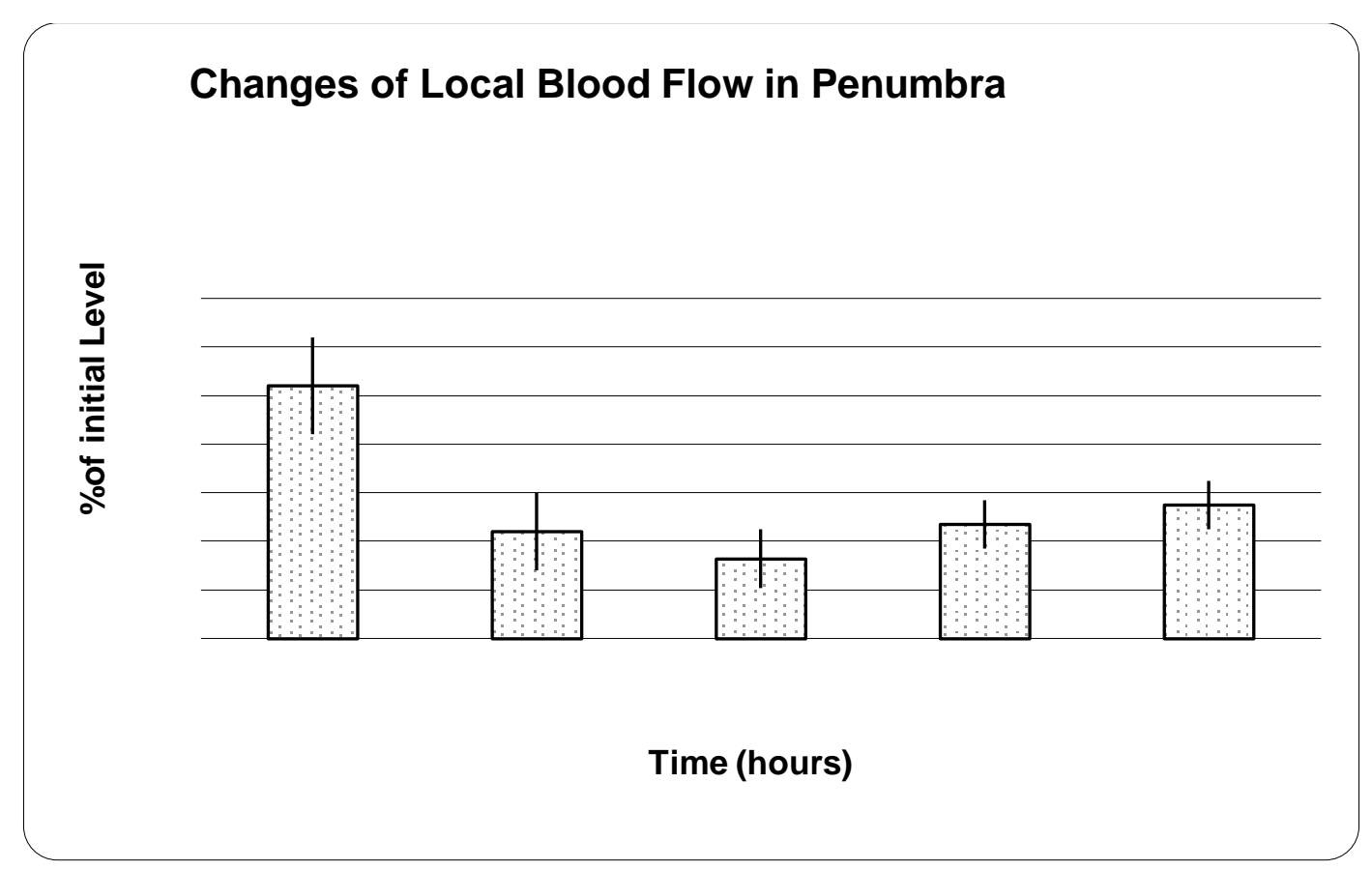

Fig. 2. Alterations in local blood flow in the Penumbra zone for 4 days

The mentioned increase in blood supply compared with the data obtained in 24 hours after illumination appeared to be statistically reliable $(\mathrm{P}<0.05)$. After two more days, i.e. 4 days after the illumination in the Penumbra zone, the level of blood flow increased by a few more percent, up to $27.5 \%$ of the control value $(17.5 \pm 0.92 \mathrm{ml} / 100 \mathrm{~g} / \mathrm{min}$ in the Penumbra zone and $63.6 \pm 3.3 \mathrm{ml} / 100 \mathrm{~g} / \mathrm{min}$ on the contralateral side). In this case, improving the blood supply to the Penumbra zone is statistically reliable as well, in comparison with the previous ( 48 hours) data $(\mathrm{P}<0.05)$.

Consequently, according to the data above, the maximum reduction in blood supply to the Penumbra zone was achieved in 24 hours after the completion of the process inducing blood vessel thrombosis, and later a partial restoration of its level has been observed. The measurements of blood flow level in the intact, contralateral to the cerebral cortex infarction side, showed that in all animal groups it varied between 46 (minimum level) and $75 \mathrm{ml} / 100 \mathrm{~g} / \mathrm{min}$ (maximum level) and no statistically reliable difference has been observed in the groups of experimental animals. A similar picture was revealed regarding to systemic blood pressure. In all animal groups this indicator varied within 79 (minimum value) and $117 \mathrm{~mm} \mathrm{Hg}$. (maximum level). In this case, no statistically reliable difference between the average values according to the animal groups has been observed.

Ischemic penumbra was first defined by Astrup et al. as a zone with moderate ischemia, reduced electrical activity, but supported membrane functions, therefore, nerve tissue was still viable (Astrup et al., 1977). In case of normal blood flow restoration in the penumbra zone within 6-8 hours after ischemic stroke, the developed neurologic deficit can be compensated.

According to some studies the results of measurements of blood flow level, conducted within 6 hours did not reveal any extension of penumbra zone (i.e., a moderate ischemia zone), occurring around a well-defined central infarction zone (Kaufmann et al., 1999).

Despite this, according to a large number of studies providing the measurements of local blood flow in the brain, no more than 1-2 hours from the moment of stroke occurrence should be considered as time for real therapeutic window. Only in this case, as a result of intensive measures, can be expected a reduction in infarction volume. As usual, such measures include the use of preparations promoting reperfusion or enhancing tolerance to ischemia. As it is believed the character of cerebral infarction development primarily depends on the duration and severity of ischemia. Experimental data showed that at severe ischemia, even one hour is sufficient for formation of the infarction (Saver, (2006). It has been revealed that a decrease in blood flow in the area of cerebral ischemia to $8 \mathrm{ml} / 100$ $\mathrm{g} / \mathrm{min}$ within one hour guarantees leading to the infarction (Yonas et al., 1990). The conclusions drawn from the results of computed tomography (CT) appeared to be close to the above-mentioned - blood flow intensity $9 \mathrm{ml} / 100 \mathrm{~g} / \mathrm{min}$ should be considered as the threshold of cerebral vitality. Below this threshold, cerebral infarction will be formed within two hours (Touho, Karasawa, 1996). 
The changes/alterations in cerebral blood flow developed within the first hour are of predictive value - since, as it turned out, according to these changes, the potential possibilities for development of infarction can be predicted with some certainty (Powers et al., 1985). Thanks to the above mentioned and many other data, the assessment of brain tissue functional abilities in the center of infarction, as well as Penumbra zone and surrounding area according to the indications of local blood flow level has become a regular practice (Furie et al., 2011). The level of local blood flow is considered as the most simple and physiologically most reliable indicator objectively and unambiguously allowing to determine the state of the nervous tissue in the zone of ischemic injury and adjacent areas. Not only the depth of ischemia, but also its duration is of fundamentally importance for infarct formation. At permanent stroke or a long-term interruption of blood supply to the nervous tissues, the infarction develops in the focus of stroke as well as in the Penumbra zone (Zhao et al., 1997). In addition, it should be noted that in the area surrounding the Penumbra, only the single neurons, with the density inadequate to formation of the infarction focus, can die. Focal ischemia is not a unique phenomenon and may be of a different nature. At its early stage, due to the activation of sodium transport across the blood-brain barrier (BBB) into the ischemic zone, significant intercellular edema might be developed (Shalvi Mahajan, Hemant Bhagat, 2016). Reperfusion, as well as prolonged or permanent ischemia, in its side, can lead to very dramatic outcomes.

Rather thorough experimental studies have shown absence of direct correlation between reduced post-ischemic blood flow and further extension and aggravation of the infarction, at both global and in focal ischemia. In the doomed to infarction penumbra zone, an hour after ischemia glucose consumption was reduced by $50 \%$ or more while at the post-ischemic period a close correlation between low glucose metabolism and local blood flow has been observed (van Golen et al., 2013). At the post-ischemic period of temporal focal ischemia (during the first 12 hours after its cessation), the focal area itself has a normal blood flow level, but penumbra - usually about $40-50 \%$ of the norm, respectively (Nagasawa et al., 1989). However, like a global ischemia, no evidences of impaired correlation between blood flow and metabolism were seen. In some cases, the conducted measurements showed that the ATP level at this time is within 70 and $100 \%$ of pre-ischemic level and is not considered as a very significant decrease. According to Chen et al. a very clear correlation between increased post-ischemic blood flow and decreased infarction size has been shown, in terms of inhibition of prostaglandin synthesis (Chen et al., 1995).

There are lots of other potentially positive effects of blocking the prostaglandin metabolism (with the exception of vasodilation), for example, prevention of free radical production.

The conducted experimental studies do not indicate to the principal importance of the increase of post-ischemic blood flow to prevent the penumbra zone from development of possible ischemic injuries, which is well in line with the concept based on functioning of the conjugation: "functionmetabolism-blood flow".

In other words, at this stage, concerning the ideas about the significance of blood supply in formation of ischemic brain injuries, it could not be approved with certainty that neither at global nor focal ischemia that the main cause for development and extension of the injury is the reduction in blood supply at the post-ischemic period, since it is "dictated" by a decrease in the intensity of metabolism.

Therefore, an increase in local post-ischemic cerebral blood flow can hardly be of protective nature (KUNZ and IADECOLA, 2009). This, at first glance paradoxical conclusion, should not reduce potentially critical sensitivity of ischemic injury to the level of blood supply at stroke, especially at focal, temporary ischemia when the penumbra blood flow level is within the range of "too damaging" and "simply damaging".

In our experiments, a permanent (or prolonged up to the completion of experience) ischemia, when it's useless to discuss the role of not-existed reperfusion (if not induced by any pharmacological route) was considered. It might be possible that, the absence of reperfusion at permanent ischemia with all the relevant dramatic changes (damage to endothelial cell layer, with protein release at the 30 th minute of reperfusion) leads to a partial improvement (shown in our experiments) of the both tissue blood supply and its morphological picture.

There is no doubt that the use of various experimental models of cerebral stroke and the study of morphological, biochemical and functional disorders developing in the damaged area of the brain in experimental animals are of great importance to detect the mechanisms and course of stroke as well as providing early treatment. It is also clear that each experimental model only partially reflects the ischemic changes occurring in the human brain.

Therefore, using the different models of cerebral ischemia is complementary that makes it possible to get closer to identifying the intimate mechanisms of human stroke. 
In the literature, there are a number of data indicating that along with the so-called "Occlusal" models (for example, a model based on SCA occlusion), a photochemical model of local cerebral infarction most precisely reflects human brain ischemic injury (Van Gelderan et al., 1994).

Despite the fact that photochemically induced injuries are the result of the fast progressing disorders, destruction of the blood-brain barrier and vasogenic edema, cell changes in the ischemic focus occur for quite a long time and have the same tendencies as at using "occlusal" models (Lee et al., 1996).

It should also be noted that in comparison with the "occlusal" models, the model of photochemically induced local ischemia is characterized by very good ergonomics: easily implementable, reproducible, relatively non-invasive and, although it is assumed that this model does not reflect the clinically observed ischemic changes, Apparent Diffusion Coeficient -ADC and cellular changes are very similar to those occurring at stroke (Purushotham et al., 2015). In addition, this method can be successfully applied not only to detect the fundamental mechanisms for progression of ischemic brain injury at developed local infarction of hemispheres of cerebral cortex and to search for new effective approaches and methods of therapy, but to conduct research aimed at detecting the roles of individual regions and zones of cerebral cortex in implementation of such fundamental functions as learning, memory, behavior, etc. (for example, Kelly et al., 2001; Diehm et al., 2003; Reinecke et al., 2003, and others).

Conclusions. It has been revealed that the maximum reduction in blood supply in the penumbra zone during permanent ischemia is achieved 24 hours after the completion of the process of inducing thrombosis of vessels. Therapeutic intervention to save the cells of the Penumbra zone, which are in the initial stages of apoptosis, it is advisable to carry out in the first 12 hours after the onset of stroke.

\section{REFERENCES}

1. Ahmed S-H., Shaikh A. Y., Shaikh Z. Y., Hsu C. Y., 2000. What animal models have taught us about the treatment of acute stroke and brain protection. Curr. Atheroscler. Rep., 2, 167-180.

2. Astrup J., Symon L., Branston N., Lassen N., 1977. Cortical evoked potential and extracellular $\mathrm{K}^{+}$and $\mathrm{H}^{+}$ at critical levels of brain ischemia. Stroke, 8, 51-57.

3. Bhardwaj A. J., Alkayed N. J., Kirsch J. R., Hurn P.D., 2003. Mechanisms of ischemic brain damage. Curr. Cardiol. Rep.,5, 160-167.

4. Chen J., Weinstein P., Graham S., 1995. Attenuation of postischemic brain hypoperfusion and reperfusion injury by the cyclooxygenase-lipoxygenase inhibitor BW755C. J, Neurosurg., 83, 99-104.

5. Diehm S. M., Witte O. W., Bruehl C., 2003. Differential alterations of the inactivation properties of high voltage activated calcium currents in area CA1 and CA3 $\mathrm{f}$ the rat following photothrombotic lesion. Neurosci. Lett., 341, 147-150.

6. Dietrich W. D., Watson B.D., Busto R., Ginsberg M. D. Bethea J. R., 1987. Photochemically induced cerebral infarction, I: early microvascular alterations. Acta Neuropathol. (Berl.), 72, 315-325.

7. Furie KL, Kasner SE, Adams RJ, et al., 2011. Guidelines for the Prevention of Stroke in Patients with Stroke or Transient Ischemic Attack: A Guideline for Healthcare Professionals from the American Heart Association/American Stroke Association. Stroke. 42, 1, 227-76.

8. Kaufmann A., Firlik A., Melanie D., Fukui B., Wechsler L., Jungries A., Yonas H., 1999. Ischemic core and penumbra in human stroke. Stroke, 30, 93-99.

9. Kelly K. M., Kharlamov A., Hentosz T. M., Kharlamova E. A., Williamson J. M., Bertram E. H., Kapur J., Armstrong D. M., 2001. Photothrombotic brain infarction results in seizure activity in aging Fischer 344 and Sprague Dawley rats. Epilepsy Res.,47, 189-203.

10. Kunz Alexander and Iadecola Costantino., 2009. Cerebral vascular dysregulation in the ischemic brainHandb Clin Neurol., 92: 283-305. doi: 10.1016/S0072-9752(08)01914-3

11. Lee V. M., Burdett N. G., Carpenter T. A., Hall L. D., Pambikain P. S., Patel S., Wood N. I., James M. F., 1996. Evolution of photochemically induced cerebral ischemia in the rat. Stroke, 27, 2110-2119.

12. Lehrmann E., Christensen T., Zimmer J., Diemer N. H., Finsen B., 1997. Microglia and macrophage reactions mark progressive changes and define the penumbra in the rat neocortex and striatum after transient middle cerebral artery occlusion. J. Comp. Neurol., 386, 461-476.

13. Mitagvaria N., Nebieridze M., Kakabadze T., Erkomaishvili I. Sildenafil citrate (viagra) aggravates development of cerebral infarction. 2001, Clin. Hemorheol. and Microcircul., 24, 212-213.

14. Mitagvaria N., Bakhutashvili V., Sanikidze T., Nebieridze M., Pipia N., 2001, Plaferon-LB prevents development of cerebral infarction after photochemically induced thromboses in the rats. Georgian $\mathbf{J}$ Neuroscien., 1, 13-27.

15. Nagasawa H., Kogure K., 1989. Correlation between cerebral blood flow and histological change in a new rat model of cerebral artery occlusion. Stroke, 20, 1037-1043.

16. Powers W., Grubb R., Darriet D., Raichle M., 1985. Cerebral blood flow and cerebral metabolic rate of oxygen requirements for cerebral function and viability in humans. J. Cereb. Blood Flow Metab., 5, 600-608. 
17. Purushotham A, Bruce C. V. Campbell, Matus Straka, et al. 2015. Apparent diffusion coefficient threshold for delineation of ischemic core. Int J Stroke. 10, 3, 348-353.

18. Ramos-Cabrer P, Campos F, Sobrino T, Castillo J., 2011. Targeting the ischemic penumbra. Stroke. 42 (1 Suppl): S7-11. doi: 10.1161/STROKEAHA.110.596684

19. Reinecke S., Dinse H. R., Reinke H., Witte O.W., 2003. Induction of bilateral plasticity in sensory cortical maps by small unilateral cortical infarctin in rats. Eur. J. Neurosci., 17, 623-627.

20. Saver J.L., 2006. "Time is brain - quantified". Stroke. 37, 1, 263-6. doi: 10.1161/01. STR.0000196957. 55928.ab

21. Shalvi Mahajan, Hemant Bhagat, 2016, Cerebral oedema: Pathophysiological mechanisms and experimental therapies. Journal of Anesthesiology and Critical Care. CONFERENCE PROCEEDING, 3, 4, 22-28.

22. Van Gelderan P., de Vleeschouwer M. H. M., DesPres D., Pekar J., van Ziyl P. C. V., Moonen C. T., 1994. Water diffusion and acute stroke. Magn. Reson. Med., 31, 154-163.

23. Van Golen, Marc C. Huisman, Richard G. Ijzerman, et al., 2013. Cerebral Blood Flow and Glucose Metabolism Measured with Positron Emission Tomography Are Decreased in Human Type 1 Diabetes. Diabetes Aug; 62, 8, 2898-2904. https://doi.org/10.2337/db12-1159

24. Van Reempts J., Van Deuren B., Van de Ven M., Cornelissen F., Borgers M., 1987. Flunarizine reduces cerebral infarct size after photochemically induced thrombosis in spontaneously hypertensive rats. Stroke, $18,1113-1119$.

25. Wang G. X., Li G. R., Wang Y. D., Yang T. S., Ouyang Y. B., 2001. Characterization of neuronal cell death in normal and diabetic rats following experimental focal cerebral ischemia. Life Sci.,69, 2801-2810.

26. Watson B. D., Dietrich W. D., Busto R., Watchel M. S., Ginsberg M. D., 1985. Introduction of reproducible brain infarction by photochemically initiated thrombosis. Ann. Neurol., 17, 497-504.

27. Yonas H., Gur D., Classen D., Wolfson S.K., Moossy J., 1990. Stable xenon enhanced computed tomography measurement of cerebral blood flow in reversoble focal ischemia in baboons. J. Neurosurg., 73, 266-273.

28. Zhao Q., Belaiev L., Ginsberg M., 1997. Transient middle cerebral artery occlusion by intraluminal suture. II Neurological deficits and pixel-based correlation of histopathology with local blood flow and glucose utilization. J. Cereb. Blood Flow Metab., 17, 1281-1290.

29. Zhao F., Kuroiwa T., Miysaka N., Nagaoka T., Nakane M., Tamura F., Mizusawa H., 2001. Characteristic changes in T(2)-value, apparent diffusion coefficient, and ultrastructure of substantia nigra evolving exofocal post-ischemic neuronal death in the rat. Brain Res., 895, 238-244.

30. Zhao F., Kuroiwa T., Miysaka N., Nagaoka T., Nakane M., Tamura F., Mizusawa H., 2002. Ultrastructural and MRI study of the substantia nigra evolving exofocal post-ischemic neuronal death in the rat. Neuropathol., 22, 91-105. 